\title{
Children's sunburn exposed: Identification of sun exposure and parental sun protection patterns
}

\author{
K. Thoonen ${ }^{\mathrm{a}}$, V. Lima Passos ${ }^{\mathrm{b}}$, F. Schneider ${ }^{\mathrm{a}}$, H. de Vries ${ }^{\mathrm{a}}$, L. van $\mathrm{Osch}^{\mathrm{a}}$ \\ ${ }^{\text {a }}$ Department of Health Promotion, School CAPHRI, Maastricht University, Maastricht, the \\ Netherlands \\ ${ }^{\mathrm{b}}$ Department of Methodology and Statistics, School CAPHRI, Maastricht University, \\ Maastricht, the Netherlands
}

\section{Additional information}

Corresponding author

Karlijn Alexandria Henrieke Josephine Thoonen

P. Debyeplein 1, 6229 HA Maastricht, the Netherlands

karlijn.thoonen@maastrichtuniversity.nl 


\begin{abstract}
Background: Preventing sunburn in childhood is imperative in the light of skin cancer prevention. To provide directions for targeted interventions, a better understanding of children's sunburn and associated parental behaviours is necessary.

Objective: To explore sun exposure and parent-for-child sun protection patterns and their relation with experienced sunburn in children.

Materials \& Methods: An online survey study was conducted among parents $(n=1299)$ of children (4 to 12 years). Latent Class Analysis (LCA) was performed to identify parental subgroups in children's sunburn, sun exposure and several sun protection behaviours (i.e. applying sunscreen, clothing, seeking shade) in two sun exposure settings (i.e. planned versus incidental). LCA results were validated by assessing predictions of class membership through several socio-demographic characteristics.

Results: Reported sunburn in the previous year was frequent $(>40 \%)$. Four latent classes of sunburn-exposure-protection were identified. Overall, the majority of parents reported fair sun protection behaviours. While lower protection behaviours were not strongly reflected in lower sunburn rates among the classes, high amounts of planned exposure (e.g. going to the beach) seemed to correspond with higher sunburn risk. Parents of younger children and those with more sensitive skin, reported sun protection measures more frequently. Older children and those with more sensitive skin experienced more sunburn.

Conclusion: This study contributes to current insight in children's sunburn, based on parentproxy reports. Although a clear differentiation in sunburn risk was not found, several groups relevant for future interventions were indicated. By revealing the complexity of children's sunburn, suggestions for further research are provided.
\end{abstract}

Key words: children's sun safety, parental behaviour, sun exposure, sun protection behaviours sunburn 


\section{Introduction}

Melanoma and non-melanoma skin cancers (NMSC) are some of the most rapidly increasing malignancies worldwide, affecting especially fair-skinned populations (1). Since the late 1980s, skin cancer incidence has tripled in the United States $(2,3)$ and nearly quadrupled in the Netherlands $(4,5)$. Age-standardized incidence rates were estimated at 12.7 for the United States, compared to 25.7 for the Netherlands, 27.6 for Denmark, and 33.6 for Australia per 100,000 cases respectively in 2018 (6). Globally, melanoma represents the most fatal form of skin cancer and its incidence has risen more rapidly than any other malignancy in the last 50 years $(3,7)$.

Overexposure to Ultraviolet radiation (UVR) and sunburn are major risk factors for developing melanoma, particularly when acquired during childhood $(8,9)$. A meta-analysis revealed that having experienced sunburn at least once during childhood almost doubles the risk of developing melanoma (10). Additionally, although UVR-exposure throughout life increases melanoma risk, children's skin is more susceptible to damage, and the harmful effects can latently persist until adulthood (11-13). Children's skin has lower levels of protective melanin, resulting in a deeper penetration of UVR and greater damage to the skin (13). Limiting the amount of UVR and reducing sunburn incidence during childhood is therefore especially important. However, sunburn prevalence among children is still high, with reported percentages of children having experienced sunburn at least once during the previous year ranging between $29 \%$ to over $60 \%$ in the Netherlands, United States, Denmark and Switzerland (14-18). Factors associated with increased sunburn risk among children, such as older age, sun-sensitive skin $(14,19)$, and past sunburn of parents or children (18-20) were previously reported.

Preventing sunburn among children is of utmost importance. To protect the skin and prevent sunburn in children, several precautions can be taken, such as seeking shade, wearing UV- protective clothing and applying sunscreen (21). Performing these behaviours simultaneously is recommended, and should start in early life $(22,23)$. Sunscreen undoubtedly remains the measure applied most frequently (24-28) and is often used as sole prevention method among parents $(29,30)$. Seeking shade and wearing protective clothing are also considered highly important in order to enhance sun safety $(12,29,31,32)$, but sunscreen is still advised to be applied as an adjunct to other forms of sun protection $(21,34)$.

Parents and caregivers are crucial in establishing children's sun safety and subsequent prevention of sunburn experiences. They are primarily responsible for the application of sun protection measures for their children (28) and are most important in teaching children to perform their own sun protection behaviours (20). The large amount of influence of parents as 
active agents and role models is well reflected in strong correlations between parents' own sun protection behaviour and their children's sun safety $(18,35,36)$. Parents are therefore recommended to strictly adhere to sun protection guidelines and to teach their children adequate sun protection behaviours $(37,38)$, rendering them an essential target group for communications and interventions aimed at preventing children's sunburn.

Despite various studies reporting on parent-for-child sun protection behaviours, the association between the amount of children's UVR-exposure and performance of parent-forchild sun protection behaviours is underexplored. Equally unknown is how this exposureprotection connection affects children's sunburn experiences. Previous studies have focused on very young children $(36,39,40)$, on nevus development rather than sunburn experiences $(41$, $42)$, or did not report sun exposure patterns $(31,43)$. The link between sun exposure, sun protection behaviours and sunburn is regarded as complex and needs further clarification. Hence, in order to gain insight in children's sunburn, identification of risk-patterns of UVRexposure and parent-for-child sun protection behaviours in various situations is necessary.

The extent to which sun protection behaviours are necessary depends on the activities in which sun exposure is acquired. For example, when not actively focused on spending time outdoors, preparation efforts to protect ones' skin may be lower than when people intentionally expose themselves to the sun $(44,45)$. Consequently, the risk of sunburn increases in these unintentional sun exposure situations (e.g. playing outdoors) due to limited shade availability, prolonged duration of the exposure, or reliance on sunscreen use only, as shown by a recent study among adolescents and adults in New Zealand (46), and in Denmark (47). Two German studies among parents of very young children ( 3 to 6 years) revealed different parent-for-child sun protection behaviours: shade-seeking behaviour and wearing hats and sunglasses were applied more often in a beach setting than during everyday outdoor activities (48, 49). Moreover, parental sun protection behaviours among older children vary across sun exposure situations $(25,50,51)$, and their relationship with sunburn is largely undocumented. There is evidence that the more intense and intermittently received UVR, e.g. during recreational activities, the greater the melanoma risk $(8,52)$. Therefore, shedding light on the association of different types of sun exposure, sun protection strategies and their relation to children's sunburn is expected to generate a better understanding of sunburn risk in different exposure settings. This knowledge would facilitate the development and implementation of targeted policy and interventions to counteract the increasing melanoma incidence rates.

This study aimed to explore the heterogeneity of inter-relations between: (1) children's sun exposure; (2) parental sun protection behaviours; and (3) children's sunburn frequency. To 
achieve this goal, we applied latent class analysis (LCA), a model-based clustering technique (53), to empirically derive typologies capturing distinct patterns of inter-connections across the three domains. Further, links between the identified classes and parental and children's sociodemographic characteristics were investigated to explore possible subgroups that deserve specific attention in future interventions.

\section{Materials and methods}

\section{Procedure and participants}

This study was part of a longitudinal survey study whose data from the baseline measurement (June 2016 (T0)) was analysed. The study was exempt from medical ethical evaluation since participants were not exposed to medical procedures (54). The collected data was not traceable to specific participants in the dataset (55).

Eligible participants, caring for at least one child of primary school age (4 to 12 years), were retrieved from an existing research panel and received one invitational and one reminder email. A sample of 2449 parents, representative of the Dutch general population according to education level and income, were approached by research organisation TNS-KANTAR. Informed consent was acquired online (56). In total, 1299 Dutch parents filled in the online questionnaire. Parents obtained gift vouchers after completing the survey.

\section{$\underline{\text { Measurement }}$}

The online questionnaire assessed, amongst others, 1) demographic characteristics; 2) children's sunburn experiences; 3) the amount of children's sun exposure; and 4) parental sun protection behaviours (i.e. sunscreen use, clothing, and seeking shade) in both planned and incidental sun exposure situations. Planned situations concerned sun exposure that is generally anticipated by the parent and/or the child (e.g. going to the beach or swimming pool), whereas incidental situations consisted of less intentional sun exposure situations (e.g. when walking, cycling or playing outdoors). Children's sunburn, sun exposure and sun protection behaviours during the previous summer season were assessed for the youngest child in the parents' household. The full questionnaire can be retrieved from Open Science Framework (OSF): https://osf.io/zncwq/. This study is reported in accordance with STROBE guidelines for observational research (57). 


\section{1) Socio-demographic characteristics}

Parental and children's age, sex, skin type and parental educational level and province of residence were assessed. Parental age was categorized in three groups (18-34 years, 35-44 years, and $\geq 45$ years), as was children's age ( 4 to 6 years, 7 to 9 years, and $\geq 10$ years), the latter in agreement with the Dutch primary school system. Age categories were referred to as young, middle-aged and older. Parental and children's skin type was categorized in: I) burns very quickly, tans never or rarely; II) burns quickly, tans slowly; III) burns rarely, tans easily; and IV) burns almost never, tans very easily. Educational level was classified in lower (1), intermediate (2) and higher (3) education, cf. guidelines of Statistics Netherlands (58). The twelve Dutch provinces of residence were subdivided into North (1), East (2), West (3) and South (4), cf. classification of Dutch Ministry of the Interior and Kingdom Relations (59).

\section{2) Children's sunburn}

The frequency of children's sunburn was assessed using one item, in which parents were asked how often their child had experienced sunburn in the past 12 months. A 5-point Likert scale was used (never (1), 1-2 times (2), 3-4 times (3), 4-5 times (4) and > 5 times (5)).

\section{3) Children's sun exposure}

The amount of received sun exposure was assessed by asking parents the frequency with which their child was outside on sunny days during the previous 12 months, using a 5-point Likert scale (never (1), rarely (2), sometimes (3), often (4), as often as possible (5)). The questions regarding sun exposure were asked using two items; one regarding planned situations and one for incidental situations. Planned sun exposure involved intentional sun-seeking behaviour (e.g. going to the beach or swimming pool) and incidental sun exposure consisted of all other situations in which children were sun-exposed (e.g. playing outdoors, cycling). Parents received an explanatory text regarding how to distinguish between these sun exposure situations.

\section{4) Parental sun protection behaviours}

Three parent-for-child sun protection behaviours were assessed: 1) sunscreen use; 2) clothing; and 3) seeking shade. The execution of these behaviours was asked about regarding the two (planned and incidental) sun exposure situations, resulting in six items. A 5-point Likert scale was again used to assess the frequency of sun protection behaviours (never (1), rarely (2), sometimes (3), often (4) and always (5)). Sufficient sunscreen application encompassed using an $\mathrm{SPF} \geq 30$, applying sunscreen 30 minutes prior to sun exposure, and reapplying sunscreen 
every two hours. For clothing, wearing a shoulder-covering T-shirt, wearing a hat and wearing sunglasses was regarded as sufficient. Lastly, seeking shade between UV-peak hours, 12 and 3 PM, was considered adequate. Explanatory text regarding the sufficient performance of sun protection behaviours was provided in the questionnaire (https://osf.io/zncwq/).

\section{Variables operationalisation}

Data preparation for statistical analyses took place by recoding the categorical variables. An inspection of the answers' frequency distribution showed very low count in some response categories. For this reason, all categorical variables were collapsed to avoid sparsity problems. Children's sunburn frequency was recoded as never (1), 1-2 times (2), >3 times (3), while children's sun exposure in both planned and incidental situations was recoded as never (1), rarely and sometimes (2), often and as often as possible (3), and parental execution of sun protection behaviours in both sun exposure situations as never (1), rarely and sometimes (2), often and always (3). Based on this recoding, three answer categories were obtained across all items. First, the least protective answer category included the responses of $>3$ sunburn experiences, highest reported levels of sun exposure and lowest reported levels of sun protection behaviours. Second, the intermediate answer category contained responses of 1-2 sunburn experiences, being rarely and sometimes sun-exposed, and having rarely and sometimes performed sun protection behaviours. Lastly, the most optimal answer category consisted of the responses of having never experienced sunburn, lowest reported level of sun exposure and highest levels of reported sun protection behaviours.

\section{$\underline{\text { Statistical methods }}$}

Descriptive statistics (means, standard deviations and percentages) were computed to examine the distribution of participants' characteristics, children's sunburn frequency, children's sun exposure and the frequency of parental sun protection behaviours. McNemar-Bowker and Chisquare tests were conducted to explore differences in sample protection behaviours in planned vs. incidental sun exposure situations and for sunburn frequency, respectively. Significance level was set at 5\%. IBM SPSS Statistics for Windows, version 25.0, was used (60).

\section{Analysis plan}

\section{1) Latent Class Analysis - model fitting}

Latent Class Analysis (LCA), a model-based clustering technique, was conducted to explore the heterogeneity of children's sunburn and behavioural patterns (both children's sun exposure 
and parental sun protection behaviours) $(53,61)$. The non-directly observable data-driven classes were revealed by grouping participants with similar responses to items related to sunburn, sun exposure, and sun protection behaviours, but different from other groups. Classenumeration, i.e. determining the number of latent classes, was guided by the model fit Akaike Information Criterion (AIC) and adjusted Bayesian Information Criterion (BIC) (62), while visually assessing whether extracted classes were qualitatively distinct from each other. After settling for the final number of classes, post-hoc posterior probabilities of class membership is computed for each subject (53), who is then assigned to the class with the highest posterior probability. The index of entropy, though not used to guide class-enumeration, was also reported to indicate the quality of classification uncertainty (entropy values above 0.80 are considered of very good classification performance). LCA was executed using SAS software version 9.4 (63).

\section{2) Classes' profiling}

Chi-square tests were performed to explore unadjusted differences among extracted classes in socio-demographic characteristics (parental age, sex, skin type, province of residence and educational level, and children's age, sex and skin type). A multinominal linear regression model was fitted to establish which of these characteristics remained independently linked to class membership after mutual adjustment. Estimated odds ratio (OR) and 95\% Confidence Intervals (CIs) are displayed in forest plots. To avoid multicollinearity in the multinomial logistic regression, age and skin type of the child rather than of the parents were included in the model.

\section{Results}

\section{Socio-demographic characteristics}

Of the included parents, $773(59.5 \%)$ were mothers and the questionnaire was answered for 656 (50.5\%) boys. Parents' age was normally distributed (range: 18 to 69 years) and most often between 40 and 44 years old (32.6\%). Children's age was not evenly distributed, resulting in children most often being between 4 and 6 years old $(n=595 ; 45.8 \%)$. Most children had skin type III (burns rarely) (49.7\%), followed by skin type II (burns quickly) (35.9\%). Most parents received higher education $(n=625 ; 48.3 \%)$. 


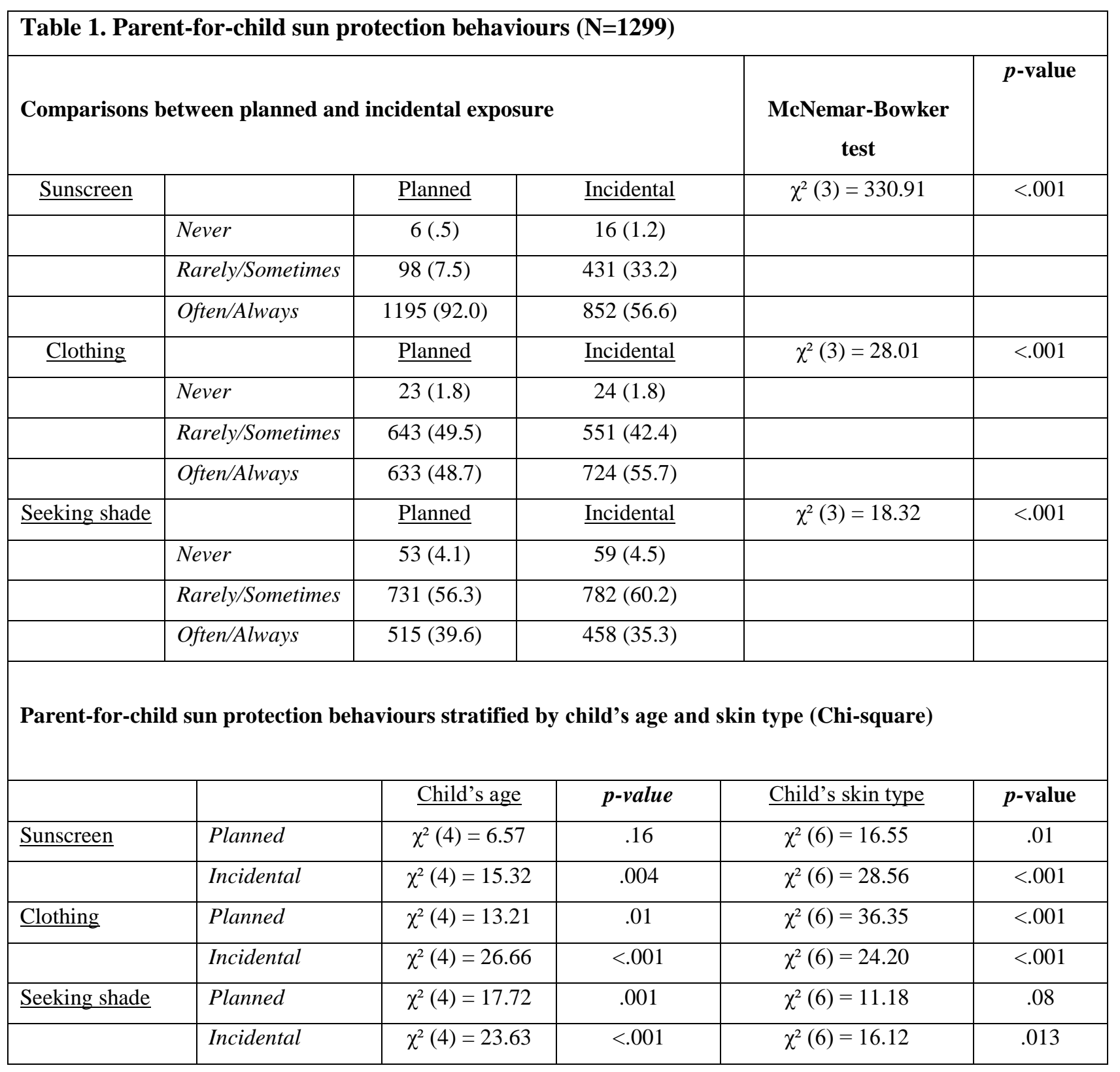

Sunburn, sun exposure and sun protection behaviours

Overall, during the previous year, 550 children (42.4\%) had experienced at least one case of sunburn. Older children $\left(\chi^{2}(4)=12.80, \mathrm{p}=.012\right)$ and children with more sensitive skin $\left(\chi^{2}(6)\right.$ $=111.52, \mathrm{p}<.001)$ experienced more sunburn. Parents of younger children and children with more sensitive skin reported more frequent execution of almost all sun protection behaviours than parents of younger children and with less sensitive skin types. Sunscreen use and seeking shade were more often performed in planned situations, and clothing in incidental situations. Table 1 provides an overall summary of the whole sample, and as such, only a general overview of the marginal distributions. A more refined glimpse into the data is provided by the LCA findings. 
Identifying subgroups (Latent Class Analyses)

Models with three to six latent classes were fitted. Table 2 shows model fit assessment criteria that were used to guide class-enumeration. They were not in full agreement, but visual inspection of the distinctiveness of the classes together with the BIC indicated that a solution with four classes was a good fit to the data (62).

\begin{tabular}{|c|c|c|c|}
\hline \multicolumn{3}{|l|}{ Table 2. Model fit evaluation of Latent Classes } \\
\hline $\begin{array}{c}\text { Number of Latent } \\
\text { Class }\end{array}$ & AIC & Adjusted BIC & Entropy \\
\hline 3 & 931.18 & 1042.78 & .88 \\
\hline $\mathbf{4}$ & $\mathbf{8 9 1 . 2 1}$ & $\mathbf{1 0 4 0 . 6 7}$ & $\mathbf{. 8 2}$ \\
\hline 5 & 862.12 & 1049.45 & .84 \\
\hline 6 & 845.25 & 1070.44 & .85 \\
\hline
\end{tabular}

Figure 1 illustrates the distinct response patterns to the sunburn, exposure and protective behaviours questions of the four extracted classes. The plot shows the probability of class members of reporting high-risk, intermediate-risk and low-risk answers to sunburn, sun exposure and sun protection items. For instance, the $y$-axis of subplot 1A shows the probability for selecting the high-risk answer category, i.e. highest frequency of sunburn ( $\leq 3$ sunburn), highest reported sun exposure (often and as often as possible) and lowest reported levels of sun protection behaviours (never performed), while the $\mathrm{x}$-axis indicates whether the situation was planned or incidental. Similarly, figures 1B and 1C show the probabilities of intermediate- and low-risk answer patterns. 


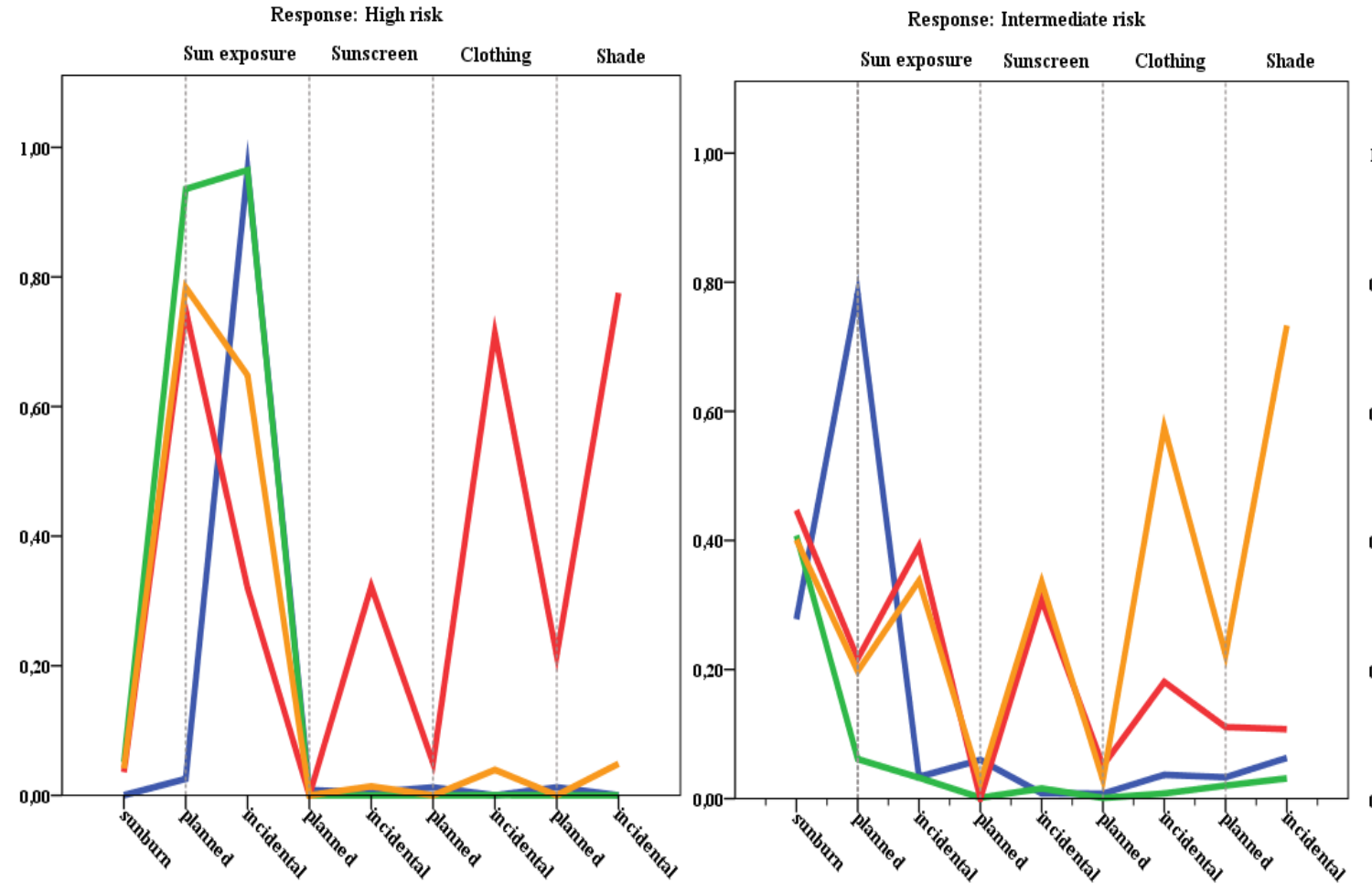

A

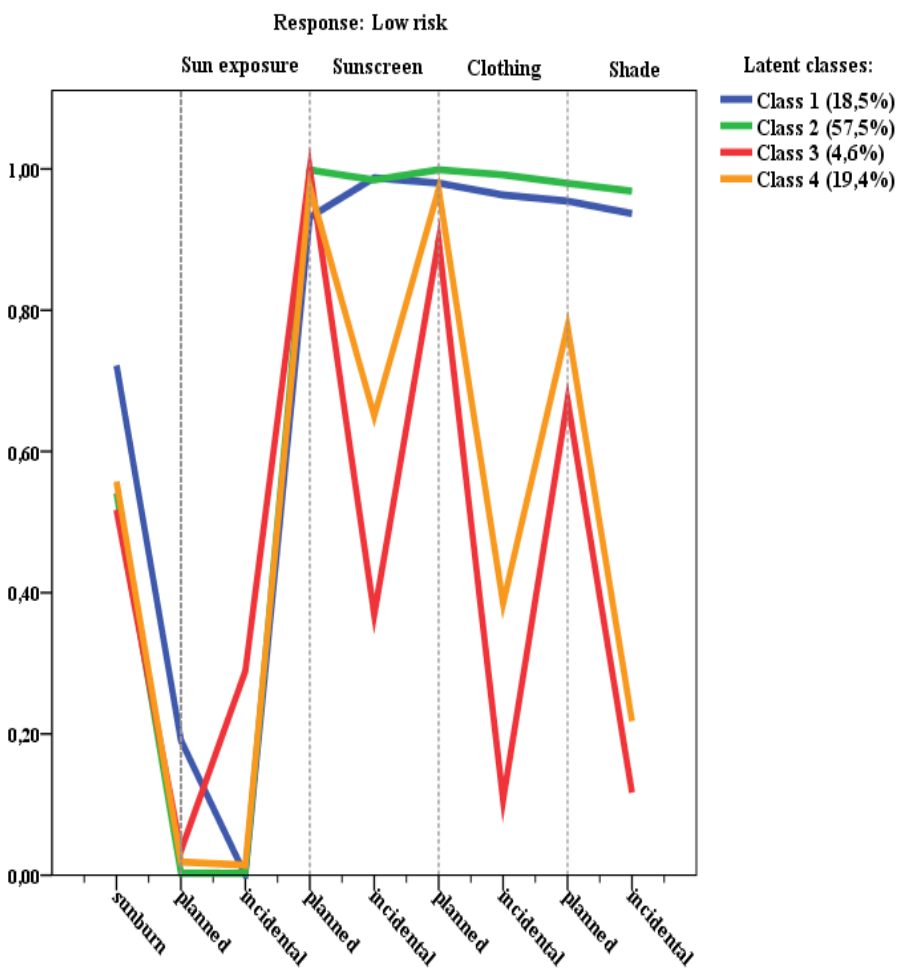

C

Figure 1. Profile plot with 4 latent classes depicting the probability (per class) of selecting the high, moderate and low risk answer category to the sunburn, sun exposure and sun protection questions. Classes' prevalence are presented as \%. 
Sunburn probability was relatively high (between $\sim 40$ and $45 \%$ for 1 or 2 cases of sunburn; $\sim 50 \%$ of no sunburn) for three out of the four classes (1B), showing a low discriminatory power between these classes for this item. Class 1 demonstrated a lower sunburn risk ( $\sim 30 \%$ of cases of 1 or 2 sunburn; $70 \%$ of no sunburn). The probability of having children with $\leq 3$ reported sunburns was very low among all classes (1A).

Sun exposure patterns showed a larger discriminatory power between classes. Class 1 and 2, which made up the majority of parents (>70\%) reported highest levels of exposure in incidental situations and the remaining classes (3 and 4) reported lower incidental exposure than planned exposure (1A). Of note, class 1 shows almost complete withholding of planned sun exposure.

Sun protection patterns are again distinct between the classes. Class 1 and 2 reported relatively high levels of sun protection behaviours in both situations, whereas the remaining two classes ( 3 and 4 ) showed more variability, with protective behaviours being more frequent in planned rather than incidental situations. The latter classes had a clear preference for sunscreen use, followed by clothing and seeking shade, respectively. Of note, these classes differed in degree of sun protection behaviours, with class 3 showing the least sun protection behaviours (Figure 1C).

The four classes were named primarily reflecting parental sun protection behaviours:

1. Class 1 with adequate sun protection behaviour $(\mathrm{n}=288 ; 30.6 \% \geq 1$ sunburn) is considered the best performing class as reflected in: a) lowest sunburn probability; b) consistent reporting of high levels of sun protection behaviour; and c) no exposure in planned situations and high exposure in incidental situations.

2. Class 2 with adequate sun protection behaviour ( $\mathrm{n}=726 ; 46.3 \% \geq 1$ sunburn), is defined as the second-best performing class as reflected in: a) moderate sunburn probability; b) consistent reporting of high levels of sun protection behaviour; and c) high levels of sun exposure in planned and incidental situations, indicating unfavourable exposure patterns.

3. Class 3 with inadequate sun protection behaviour ( $\mathrm{n}=53 ; 51 \% \geq 1$ sunburn), is considered the poorest performing class as reflected in: a) moderate sunburn probability; b) low levels of sun protection behaviours in particular in incidental situations; and c) lower levels of sun exposure in planned and especially incidental situations, indicating a more favourable exposure pattern. 
4. Class 4 with inadequate sun protection behaviour $(\mathrm{n}=232 ; 42.7 \% \geq 1$ sunburn) is defined as the intermediate performing class as reflected in: a) moderate sunburn probability; b) lower levels of sun protection behaviours; and c) lower levels of sun exposure in planned and especially incidental situations.

\section{Socio-demographic class-profiling}

Next, we compared whether parents' and children's characteristics differed across the four classes. In general, the majority of parents were middle-aged, had quickly burning (II) or rarely burning (III) skin complexions, were highly educated and lived in the Western part of the Netherlands. The majority of children also had skin type II or III. Differences in both parental and children's age and skin type (Table 3) distributions were observed across classes, with the best and second-best class including younger children with more sensitive skin types.

These differences were further confirmed after mutual adjustment (Figure 2). Results revealed that parents assigned to the best two classes had the youngest children with most sensitive skin complexions, while the best group (Class 1) included the youngest children. The two remaining classes included parents of older children, with less sensitive skin types. The total model was adjusted for parental age, sex, skin type, province of residence, educational level and children's age, sex and skin type. All model parameter estimates can be retrieved from Appendix I. 

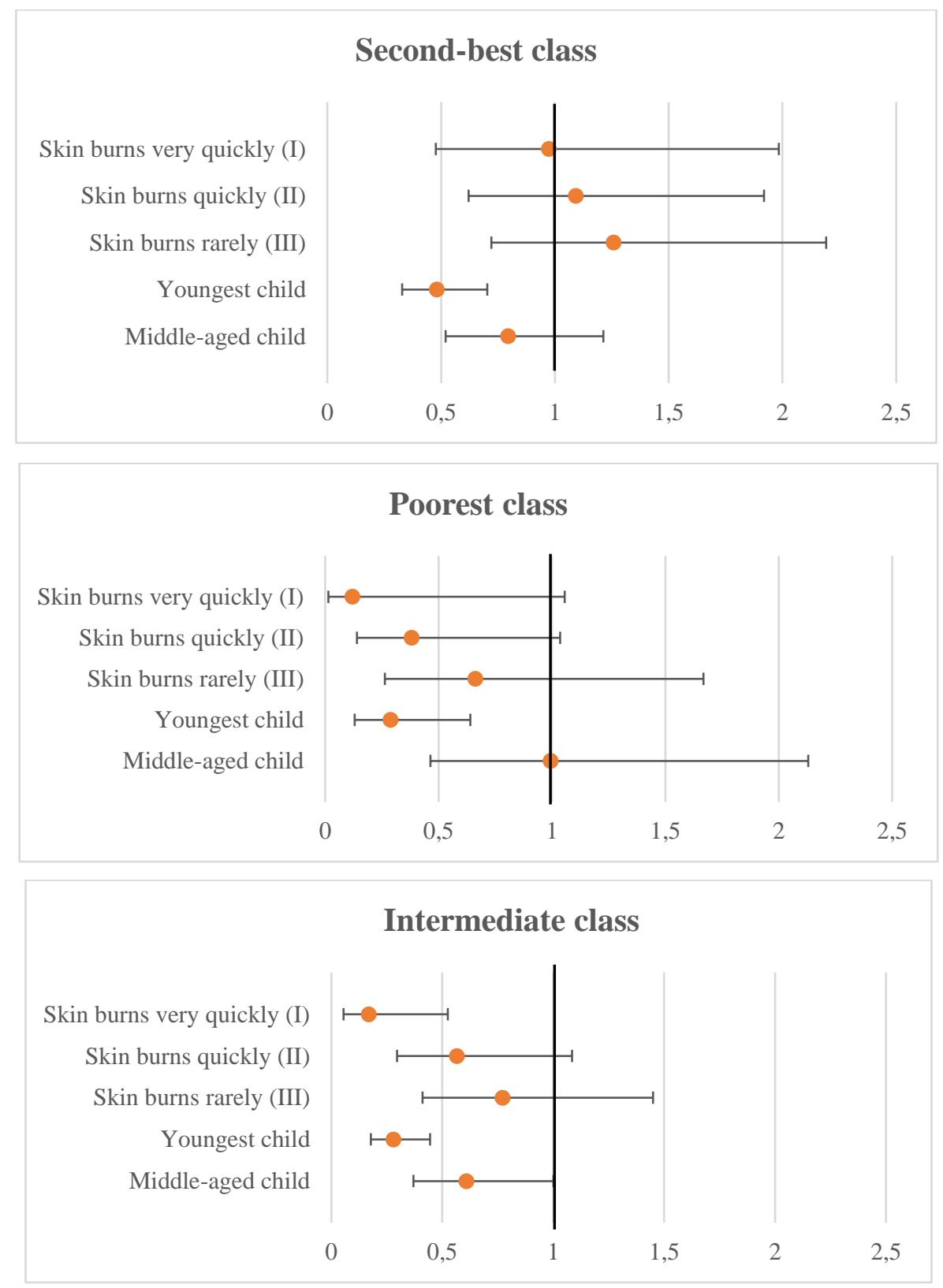

Figure 2. Forest plots with odds ratios (ORs) and associated CI's (95\%) of statistically significant results of the multinominal (multivariable) logistic regression, demonstrating socio-demographic characteristics linked to class membership - OR are provided with respect to the best class (1). Reference group for skin type is 'Skin never burns (IV)'; Reference group for children's age is 'oldest child'. 


\section{$\underline{\text { Discussion }}$}

This study exposed differences in parental sun protection, children's sun exposure patterns and children's sunburn. Overall, sunburn frequency was high ( $>40 \%)$ among all children, and parents reported fair sun protection behaviours. Latent Class analysis revealed four sun (burnexposure-protection) typologies, which, while differing in frequency and type of sun-protective strategies, could not be firmly distinguished in terms of sunburn frequency for three out of the four classes. Parents engaged in more protective measures during planned rather than incidental sun exposure. Avoiding sun exposure in these planned situations (e.g. going to the beach or swimming pool) seemed to be associated with a lower sunburn risk. These findings seem to confirm the complexity of the relationship between children's sunburn, sun exposure and parental sun protection behaviours: although the majority of parents were reporting relatively high levels of sun protection measures (Class 1 and 2), this resulted in a lower sunburn probability among only a small group of children (Class 1). This latter group included parents of young children and children with more sensitive skin types, who were inclined to limit sun exposure for their children in planned situations.

Substantial numbers of children in all four classes experienced at least one case of sunburn in the previous year, which is comparable to findings in other countries $(14-16,18)$. Parents in the best class with lowest yet notable sunburn prevalence $(>30 \%)$ were engaging in all sun protection behaviours while limiting their children's sun exposure in planned situations. They seemed to have been highly aware of the importance of sun protection behaviours and sun avoidance, but their children's sun exposure in incidental situations was still high. This may indicate, in line with previous research, that parents underestimate the risk of UVR-exposure during everyday activities $(49,64,65)$, or that they are not well prepared for sun protection in these settings (50). Parental awareness about sun exposure risk in multiple settings is therefore highly important to minimize sunburn risk, even among parents reporting high levels of sun protection behaviours.

High levels of sun protection behaviours were observed, with the majority of parents frequently reporting shade-seeking and clothing behaviours, in line with sun safety recommendations. This finding contrasts with earlier studies using comparable measures (16, $24,25,27,28,66)$. The observed discrepancy between high reported sun protection behaviours and substantial sunburn risk is noteworthy. This may indicate that, while parents may believe they are adhering to sun safety recommendations, the actual execution is suboptimal. Several studies reported on the incompleteness of sun protection measures for children. For example, 
sunscreen efficacy depends mainly on correct application patterns (67). However, sufficient sunscreen application seems particularly difficult for parents (50), as indicated by their failure to apply sunscreen 30 minutes before going outdoors (66), by skipping sensitive body parts (29), applying insufficient amounts of sunscreen (68) or not reapplying every two hours (14). Parents' erroneous perception that they have sufficiently protected their child with sunscreen may lead them to prolong their time spent in the sun, resulting in sunburn $(14,69)$. Further, studies reported that children are less likely to be protected by sunglasses and a hat than with a T-shirt (70-72), while concurrent use is recommended $(21,73)$. Hence, it is possible that the parents in the current study overestimated their adherence to specific sun protection recommendations, despite the information provided regarding sufficient sun protection in the questionnaire.

Although research on sun exposure patterns in children is scarce, recent studies from Germany reveal that the amount of time that very young children (aged 3 to 6) spend outside during peak UV hours in various settings was high (48), and that older children receive high doses of UVR in playgrounds (74). Our findings also suggest high levels of exposure, in particular among young children, in both sun exposure situations. The parents of young children reported adequate sun protection behaviours when their children were highly exposed in planned situations, but this was not echoed in low sunburn risk. A lower sunburn risk was however found among young children whose parents limited their sun exposure in planned situations. These findings emphasize the difficulty of optimal sun protection in planned sun exposure situations and may lead to the question of whether sunburn prevention is entirely possible or realistic in such situations. Protecting children sufficiently on the beach or by the swimming pool is particularly challenging, since availability of shaded areas is often lacking, sunscreen has to be reapplied more frequent clothing is perceived as burdening $(50,75)$.

Parents assigned to the best-performing class had the youngest children with more sensitive skin complexions. The higher protection for younger children is in agreement with previous research $(19,25,48)$. Since sun protection attitudes and behaviours decrease during adolescence and sunburn prevalence increases, establishing sun safety for older children is considered highly important $(16,28,43,76)$. Increased parental vigilance and sun protection behaviours among children with lighter skin types has also been described in earlier work (31, 40, 49, 50). Similarly, parents with darker skin complexions may assume that their skin phenotype protects them from UVR (39), resulting in them providing less sufficient sun protection for their children (66). The association of children's sun-sensitivity with better sun protection and thus lower sunburn rates might seem obvious, but is often not apparent $(14,16$, 
77). In the present study, a comparable relation between more sensitive skin types and high parental sun protection behaviours was found. Despite this, these children still seemed at highrisk for sunburn. The association between children's skin sensitivity, sun protection behaviours and their sunburn risk however deserves closer examination in order to compose future sun safety interventions.

\section{Strengths and limitations}

This study has several strengths that are worth mentioning. Firstly, the assessment of comprehensive sun protection behaviours in distinctive sun-exposing situations provides a novel and insightful approach compared to existing parental sun protection research. Secondly, by using a large sample size and including more than five indicators, the validity of the latent class fitting was optimized (78).

The task of exploring associations between sunburn, sun exposure and sun protection behaviours is not straightforward and is charged with some methodological challenges. Firstly, although sunburn rates in our study sample were comparable or even higher than reported sunburn in the literature, performance of parental sun protection behaviours was high. A social desirability bias could have been at play, urging parents to report more frequent protection behaviours (79). Further, since all questions were asked regarding the previous year, recall bias may have limited the accuracy of the self-reported behaviours (80). Despite our efforts to reduce these biases by stressing confidentiality and non-disclosure of the study purpose, these biases should be considered when interpreting the present findings. Secondly, sun exposure was broadly defined in this study, and details such as weather conditions, exact time of day and duration of activities were not taken into account. Self-reported sun protection has been shown to be a valid measure when contextual factors as time and activities are specifically assessed (81), or when the retrospective timeframe is as short as possible (82). Future assessment of sun exposure should ideally include tailored questions regarding specified sun-exposing situations. Lastly, the findings in this study may not readily be generalised to Dutch parents since the majority of parents received a high level of education and most children were aged between 4 and 6 years.

\section{Implications}

The majority of parents seemed to perform recommended sun protection strategies frequently, but a variability in sun protection behaviours and sun exposure patterns were also observed. Further, specific individual characteristics such as skin type and children's age explained such 
variability in part. Despite the emergence of a positive picture of sun protection behaviours, a high sunburn risk was still prevalent among the majority of children. These exploratory findings hint at directions for further research in order to investigate children's sunburn in more detail.

First, all indicators were assessed subjectively. For future efforts, we recommend the application of more objective measurements of sunburn and received UVR-exposure as well as performance of sun protection behaviours. For example, some parents have difficulty recognising sunburn as such, e.g. being unaware that reddening of the skin already signifies sunburn, leading to an underestimation of sunburn prevalence $(50,83)$. Objectively assessing sunburn and its severity would be worthwhile to improve risk-profiling (e.g. through biometric measures of melanin and erythema on the skin (84)), since sunburn and particularly severe and painful sunburn are highly correlated with melanoma development in later life (85). Further, although validation studies show fair to strong correlations between self-reported and observed exposure $(82,86,87)$, collecting objective data about children's UVR-exposure has been strongly advocated (88). Environmental effects such as shade coverage, altitude or humidity cannot be measured in self-reported questionnaires (89). Because detailed information on actual received UVR-dosage is lacking among children, the formulation of specific policy and guidelines, weighted for specific environmental characteristics (e.g. latitude, cloudiness, seasonality), cannot be formulated. As stated, parents may feel obliged to report desirable sun protection behaviours, or may overestimate their behaviours, which can both affect the validity of the findings. Investigating the execution of specific sun protection measures (e.g. using $\geq$ SPF 30, reapplication patterns (67) and wearing sunglasses as well as a hat) could provide further insight in the execution of parental sun protection behaviours.

Second, since the findings imply that particularly planned exposure (e.g. beach or swimming pool) may increase the risk of sunburn, implementing health-promoting environmental cues in these settings are advisable $(75,90)$. For instance, by providing shade, promotion of UV-protective clothing and freely available sunscreen, both parents and children can be encouraged to perform sun protection behaviours more effectively.

Third, similar to earlier studies $(19,25,28,35)$, the present study revealed that older children seem to receive less protective behaviours from their parents, and experience more sunburn than younger children. Future interventions should target older children, especially before entering the adolescent phase $(26,77)$. 


\section{Conclusions}

This study emphasizes the complexity of the association between children's sunburn, their sun exposure and parental sun protection behaviours while indicating directions for further investigation. The findings indicate that despite fair to good reported sun protection behaviours, sunburn occurrence was still high among children. Furthermore, highest sun protection was reported for younger children with lighter skin types, which was reflected in lower sunburn risk among a small group of children. We were unable to fully unravel the underlying mechanisms of the associations between sun exposure, sun protection behaviours and sunburn. Therefore, recommendations for increasing sun safety in children are provided with a cautionary note. Further research is required to clarify these complex relations in order to improve or develop tailored interventions.

\section{Financial support}

NONE.

\section{Conflict of interest.}

NONE. 


\section{References}

1. Lai V, Cranwell W, Sinclair R. Epidemiology of skin cancer in the mature patient. Clin Dermatol 2018; 36(2):167-76. doi: 10.1016/j.clindermatol.2017.10.008

2. American Cancer Society. Cancer Facts \& Figures 2020. Atlanta: American Cancer Society; 2020. Available at: https://www.cancer.org/content/dam/cancer-org/research/cancer-facts-andstatistics/annual-cancer-facts-and-figures/2020/cancer-facts-and-figures-2020.pdf (accessed 29 Oct 2020)

3. Karimkhani C, Green AC, Nijsten T, Weinstock M, Dellavalle RP, Naghavi M, et al. The global burden of melanoma: results from the Global Burden of Disease Study 2015. Br J Dermatol 2017; 177(1):134-40. doi: 10.1111/bjd.15510

4. Hollestein L, de Vries E, Nijsten T. Trends of cutaneous squamous cell carcinoma in the Netherlands: increased incidence rates, but stable relative survival and mortality 1989-2008. Eur J Cancer 2012; 48(13):2046-53. doi: 10.1016/j.ejca.2012.01.003

5. Slaper H, Van Dijk A, Den Outer P, van Kranen H, Slobbe L. UV-straling en gezondheid: Probleemveld en kennisbasis bij het RIVM. Bilthoven: Rijksinstituut voor Volksgezondheid en Milieu (RIVM); 2017. Available at: https://www.rivm.nl/bibliotheek/rapporten/2017-0074.pdf (accessed 02 Sep 2020)

6. Khazaei Z, Ghorat F, Jarrahi A, Adineh H, Sohrabivafa M, Goodarzi E. Global incidence and mortality of skin cancer by histological subtype and its relationship with the human development index (HDI); an ecology study in 2018. World Cancer Res J 2019;6(2):e13.

7. Matthews NH, Li W-Q, Qureshi AA, Weinstock MA, Cho E. Epidemiology of melanoma. Exon Publ 2017:3-22. doi: 10.15586/codon.cutaneousmelanoma.2017.ch1

8. Gandini S, Sera F, Cattaruzza MS, Pasquini P, Picconi O, Boyle P, et al. Meta-analysis of risk factors for cutaneous melanoma: II. Sun exposure. Eur J Cancer 2005;41(1):45-60. doi: 10.1016/j.ejca.2004.10.016

9. Whiteman DC, Whiteman CA, Green AC. Childhood sun exposure as a risk factor for melanoma: a systematic review of epidemiologic studies. Cancer Causes Control 2001;12(1):69-82. doi: 10.1023/a:1008980919928

10. Dennis LK, Vanbeek MJ, Freeman LEB, Smith BJ, Dawson DV, Coughlin JA. Sunburns and risk of cutaneous melanoma: does age matter? A comprehensive meta-analysis. Ann Epidemiol 2008;18(8):614-27. doi: 10.1016/j.annepidem.2008.04.006

11. Green AC, Wallingford SC, McBride P. Childhood exposure to ultraviolet radiation and harmful skin effects: epidemiological evidence. Prog Biophys Mol Biol 2011;107(3):349-55. doi: 10.1016/j.pbiomolbio.2011.08.010

12. Quatrano NA, Dinulos JG. Current principles of sunscreen use in children. Curr Opin Pediatr 2013;25(1):122-9. doi: 10.1097/MOP.0b013e32835c2b57

13. Cestari T, Buster K. Photoprotection in specific populations: Children and people of color. $J$ Am Acad Dermatol 2017;76(3):S110-S21. doi: 10.1016/j.jaad.2016.09.039

14. Hall HI, McDavid K, Jorgensen CM, Kraft JM. Factors associated with sunburn in white children aged 6 months to 11 years. Am J Prev Med 2001;20(1):9-14. doi: 10.1016/s07493797(00)00265-8

15. Dusza SW, Halpern AC, Satagopan JM, Oliveria SA, Weinstock MA, Scope A, et al. Prospective study of sunburn and sun behavior patterns during adolescence. Pediatrics 2012;129(2):309-17. doi: 10.1542/peds.2011-0104

16. Ackermann S, Vuadens A, Levi F, Bulliard J-L. Sun protective behaviour and sunburn prevalence in primary and secondary schoolchildren in western Switzerland. Swiss Med Wkly 2016;146. doi: $10.4414 / \mathrm{smw} .2016 .14370$

17. Thoonen K, van Osch L, Crutzen R, de Vries H, Schneider F. Identification of socio-cognitive determinants of parental sun protection behaviors to optimize intervention development. [preprint] 2020. Available at: https://psyarxiv.com/yuqzd/. doi: 10.31234/osf.io/yuqzd

18. Behrens CL, Thorgaard C, Philip A, Bentzen J. Sunburn in children and adolescents: associations with parents' behaviour and attitudes. Scand J Public Health 2013;41(3):302-10. doi: $10.1177 / 1403494813476158$ 
19. Tripp MK, Peterson SK, Prokhorov AV, Shete SS, Lee JE, Gershenwald JE, et al. Correlates of sun protection and sunburn in children of melanoma survivors. Am J Prev Med 2016;51(3):e77-e85. doi: 10.1016/j.amepre.2016.02.032

20. O'Riordan DL, Geller AC, Brooks DR, Zhang Z, Miller DR. Sunburn reduction through parental role modeling and sunscreen vigilance. J Pediatr 2003;142(1):67-72. doi: 10.1067/mpd.2003.mpd039

21. US Department of Health Human Services. The Surgeon General's call to action to prevent skin cancer. Washington, DC: U.S. Dept of Health and Human Services, Office of the Surgeon General; 2014. Available at: https://www.hhs.gov/sites/default/files/call-to-action-prevent-skin-cancer.pdf (Accessed 08 Sep 2020)

22. British Colombia Centre for Disease Control. Sun Safety for Children. Vancouver; 2017. Available at: https://www.healthlinkbc.ca/hlbc/files/documents/healthfiles/hfile26.pdf (Accessed 05 Aug 2020)

23. American Cancer Society. How Do I Protect Myself from Ultraviolet (UV) Rays?. Atlanta: American Cancer Society; $2019 . \quad$ Available https://www.cancer.org/content/dam/CRC/PDF/Public/9419.00.pdf (Accessed 05 Aug 2020)

24. Johnson K, Davy L, Boyett T, Weathers L, Roetzheim RG. Sun protection practices for children: knowledge, attitudes, and parent behaviors. Arch Pediatr Adolesc Med 2001;155(8):891-6. doi: 10.1001/archpedi.155.8.891

25. Thoonen K, Schneider F, Candel M, de Vries H, van Osch L. Childhood sun safety at different ages: relations between parental sun protection behavior towards their child and children's own sun protection behavior. BMC public health 2019;19(1):1044. doi: 10.1186/s12889-019-7382-0

26. Buller DB, Cokkinides V, Hall HI, Hartman AM, Saraiya M, Miller E, et al. Prevalence of sunburn, sun protection, and indoor tanning behaviors among Americans: review from national surveys and case studies of 3 states. J Am Acad Dermatol 2011;65(5):S114. e1-S. e11. doi: 10.1016/j.jaad.2011.05.033

27. Severi G, Cattaruzza MS, Baglietto L, Boniol M, Dore J-F, Grivegnee A-R, et al. Sun exposure and sun protection in young European children: an EORTC multicentric study. Eur J Cancer 2002;38(6):820-6. doi: 10.1016/s0959-8049(02)00015-1

28. Stanton WR, Janda M, Baade PD, Anderson P. Primary prevention of skin cancer: a review of sun protection in Australia and internationally. Health Promot Int 2004;19(3):369-78. doi: 10.1093/heapro/dah310

29. Robinson JK, Rigel DS, Amonette RA. Summertime sun protection used by adults for their children. J Am Acad Dermatol 2000;42(5):746-53. doi: 10.1067/mjd.2000.103984

30. Rodvall YE, Wahlgren C-F, Ullén HT, Wiklund KE. Factors related to being sunburnt in 7year-old children in Sweden. Eur J Cancer 2010;46(3):566-72. doi: 10.1016/j.ejca.2009.09.017

31. Autier P, Doré J-F, Cattaruzza MS, Renard F, Luther H, Gentiloni-Silverj F, et al. Sunscreen use, wearing clothes, and number of nevi in 6-to 7-year-old European children. J Natl Cancer Inst 1998;90(24):1873-80. doi: 10.1093/jnci/90.24.1873

32. Linos E, Keiser E, Fu T, Colditz G, Chen S, Tang JY. Hat, shade, long sleeves, or sunscreen? Rethinking US sun protection messages based on their relative effectiveness. Cancer Causes Control 2011;22(7):1067-71. doi: 10.1007/s10552-011-9780-1

33. Watson M, Garnett E, Guy GP, Holman DM. The surgeon general's call to action to prevent skin cancer. 2014. Available at: https://stacks.cdc.gov/view/cdc/24419 (Accessed 04 Aug 2020)

34. Cooley JH, Quale LM. Skin cancer preventive behavior and sun protection recommendations. Semin Oncol Nurs 2013;29(3):223-6. doi: 10.1016/j.soncn.2013.06.008

35. Dobbinson S, Wakefield M, Hill D, Girgis A, Aitken JF, Beckmann K, et al. Children's sun exposure and sun protection: prevalence in Australia and related parental factors. J Am Acad Dermatol 2012;66(6):938-47. doi: 10.1016/j.jaad.2011.06.015

36. Bränström R, Kristjansson S, Dal H, Rodvall Y. Sun exposure and sunburn among Swedish toddlers. Eur J Cancer 2006;42(10):1441-7. doi: 10.1016/j.ejca.2006.02.008

37. Vainio H, Bianchini F. IARC Handbooks of Cancer Prevention Volume 5: Sunscreens. Oxford: Oxford University Press, 2001.

38. Saraiya M, Glanz K, Briss PA, Nichols P, White C, Das D, et al. Interventions to prevent skin cancer by reducing exposure to ultraviolet radiation: a systematic review. Am J Prev Med 2004;27(5):422-66. doi: 10.1016/j.amepre.2004.08.009 
39. Tan MG, Nag S, Weinstein M. Parental use of sun protection for their children - does skin color matter? Pediatr Dermatol 2018;35(2):220-4. doi: 10.1111/pde.13433

40. Turner LR, Mermelstein RJ. Psychosocial characteristics associated with sun protection practices among parents of young children. J Behav Med 2005;28(1):77-90. doi: 10.1007/s10865-0052565-9

41. Dodd AT, Morelli J, Mokrohisky ST, Asdigian N, Byers TE, Crane LA. Melanocytic nevi and sun exposure in a cohort of Colorado children: anatomic distribution and site-specific sunburn. Cancer Epidemiol Biomarkers Prev 2007;16(10):2136-43. doi: 10.1158/1055-9965.EPI-07-0453

42. Dulon M, Weichenthal M, Blettner M, Breitbart M, Hetzer M, Greinert R, et al. Sun exposure and number of nevi in 5-to 6-year-old European children. J Clin Epidemiol 2002;55(11):1075-81. doi: $10.1016 / \mathrm{s} 0895-4356(02) 00484-5$

43. Geller AC, Colditz G, Oliveria S, Emmons K, Jorgensen C, Aweh GN, et al. Use of sunscreen, sunburning rates, and tanning bed use among more than 10000 US children and adolescents. Pediatrics 2002;109(6):1009-14. doi: 10.1542/peds.109.6.1009

44. Reinau D, Achermann C, Arnet N, Meier C, Hatz C, Surber C. Sun protective behaviour of vacationers spending holidays in the tropics and subtropics. Br J Dermatol 2014;171(4):868-74. doi: $10.1111 /$ bjd.12995

45. McLeod G, Insch A, Henry J. Reducing barriers to sun protection-Application of a holistic model for social marketing. AMJ 2011;19(3):212-22. doi: 10.1016/j.ausmj.2011.05.008

46. McLeod GF, Reeder AI, Gray AR, McGee R. Unintended sunburn: a potential target for sun protection messages. J Skin Cancer 2017;2017. doi: 10.1155/2017/6902942

47. Køster B, Thorgaard C, Philip A, Clemmensen IH. Prevalence of sunburn and sun-related behaviour in the Danish population: a cross-sectional study. Scan J Public Health 2010;38(5):548-52. doi: $10.1177 / 1403494810371250$

48. Gefeller O, Uter W, Pfahlberg AB. Protection from ultraviolet radiation during childhood: The parental perspective in Bavaria. Int J Environ Res Public Health 2016;13(10):1011. doi: 10.3390/ijerph13101011

49. Li J, Uter W, Pfahlberg A, Gefeller O. A comparison of patterns of sun protection during beach holidays and everyday outdoor activities in a population sample of young German children. $\mathrm{Br} J$ Dermatol 2012;166(4):803-10. doi: 10.1111/j.1365-2133.2012.10805.x

50. Thoonen K, van Osch L, Drittij R, de Vries H, Schneider F. A qualitative exploration of parental perceptions regarding children's sun exposure, sun protection, and sunburn. [preprint] 2020. Available at: https://psyarxiv.com/f8brk/. doi: 10.31234/osf.io/f8brk

51. Duarte AF, Picoto A, da Costa Pereira A, Correia O. Sun protection in children: a behavioural study. Eur J Dermatol 2018;28(3):338-42. doi: 10.1684/ejd.2018.3290

52. Oliveria SA, Saraiya M, Geller AC, Heneghan MK, Jorgensen C. Sun exposure and risk of melanoma. Arch Dis Child 2006;91(2):131-8. doi: 10.1136/adc.2005.086918

53. Kongsted A, Nielsen AM. Latent Class Analysis in health research. J Physiother 2017;63(1):558. doi: 10.1016/j.jphys.2016.05.018

54. Central Committee on Research involving Human Subjects memorandum Behavioural Research. 2002. Available at: file:///D:/Libraries/Downloads/CCMO+note+Behavioural+research.pdf (Accessed 20 Jun 2020)

55. Crutzen R, Ygram Peters G-J, Mondschein C. Why and how we should care about the General Data Protection Regulation. Psychol Health 2019;34(11):1347-57. doi: 10.1080/08870446.2019.1606222

56. TNS-KANTAR. Privacy Policy Online Survey. 2019. Available at: https://www.tnsnipo.com/getmedia/e03d519b-007b-4e77-800a-f737c5eaaa3d/Privacy-Policy-Online-Survey-KantarTNS-Public-(English).pdf (Accessed 20 Jun 2020)

57. Von Elm E, Altman DG, Egger M, Pocock SJ, Gøtzsche PC, Vandenbroucke JP, et al. The Strengthening the Reporting of Observational Studies in Epidemiology (STROBE) Statement: guidelines for reporting observational studies. Int $J$ Surg 2014;12(12):1495-9. doi: 10.1016/j.ijsu.2014.07.013

58. Centraal Bureau voor de Statistiek. Standaard Onderwijsindeling. 2016. Available at: file:///D:/Libraries/Downloads/PubSoi2016_ed1920.pdf (Accessed 11 Aug 2020) 
59. Ministry of the Interior and Kingdom Relations. 2020. Available at: https://www.regioatlas.n1/indelingen/indelingen_indeling/t/provincies (Accessed 11 Aug 2020)

60. IBM Corp. Released 2017. IBM SPSS Statistics for Windows, Version 25.0. Armonk, NY: IBM Corp

61. Lanza ST, Rhoades BL. Latent class analysis: an alternative perspective on subgroup analysis in prevention and treatment. Prev Sci 2013;14(2):157-68. doi: 10.1007/s11121-011-0201-1

62. Schreiber JB. Latent class analysis: an example for reporting results. Res Social Adm Pharm 2017;13(6):1196-201. doi: 10.1016/j.sapharm.2016.11.011

63. SAS Institute Inc., Cary, NC, USA; 2020.

64. Gefeller O, Uter W, Pfahlberg AB. Good, but not perfect: parental knowledge about risk factors for skin cancer and the necessity of sun protection in southern Germany. Pediatrc Dermatol 2015;32(4):e159-e60. doi: 10.1111/pde.12572

65. Glanz K, Lew RA, Song V, Cook VA. Factors associated with skin cancer prevention practices in a multiethnic population. Health Educ Behav 1999;26(3):344-59. doi: 10.1177/109019819902600305

66. Klostermann S, Bolte G, Group GS. Determinants of inadequate parental sun protection behaviour in their children-results of a cross-sectional study in Germany. Int J Hyg Environ Health 2014;217(2-3):363-9. doi: 10.1016/j.ijheh.2013.07.013

67. de Maleissye MF, Beauchet A, Saiag P, Corrêa M, Godin-Beeckmann S, Haeffelin M, et al. Sunscreen use and melanocytic nevi in children: a systematic review. Pediatr Dermatol 2013;30(1):519. doi: 10.1111/j.1525-1470.2012.01847.x

68. Gilaberte Y, Carrascosa J. Sun protection in children: realities and challenges. Actas Dermosifiliogr (English Edition). 2014;105(3):253-62. doi: 10.1016/j.adengl.2013.05.006

69. Autier P, Boniol M, Doré JF. Sunscreen use and increased duration of intentional sun exposure: still a burning issue. Int J Cancer 2007;121(1):1-5. doi: 10.1002/ijc.22745

70. O'Riordan DL, Nehl E, Gies P, Bundy L, Burgess K, Davis E, et al. Validity of covering-up sun-protection habits: association of observations and self-report. J Am Acad Dermatol 2009;60(5):73944. doi: 10.1016/j.jaad.2008.12.015

71. Schlarbaum JP, Lazovich D, Dodd E, Hanson B, Polcari IC. Examination of use and barriers for five sun protection strategies in parents and their children. Pediatr Dermatol 2020;37(5):827-32. doi: 10.1111/pde. 14250

72. Glenn BA, Bastani R, Chang LC, Khanna R, Chen K. Sun protection practices among children with a family history of melanoma: a pilot study. J Cancer Educ 2012;27(4):731-7. doi: 10.1007/s13187-012-0377-5

73. Centers for Disease Control and Prevention. Sun Safety. 2020. Available at: https://www.cdc.gov/cancer/skin/basic_info/sun-safety.htm. (Accessed 08 Aug 2020)

74. Schneider S, Bolbos A, Kadel P, Holzwarth B. Exposed children, protected parents; shade in playgrounds as a previously unstudied intervention field of cancer prevention. Int J Environ Health Res 2020;30(1):26-37. doi: 10.1080/09603123.2019.1572105

75. Thoonen K, Osch Lv, Vries Hd, Jongen S, Schneider F. Are Environmental interventions targeting skin cancer prevention among children and adolescents effective? A Systematic Review. International Int J Environ Health Res 2020;17(2):529. doi: 10.3390/ijerph17020529

76. Fitch-Martin AR, Menger LM, Loomis AD, Hartsough LE, Henry KL. "We Don't Really Do Anything Unless it's Really Bad": Understanding Adolescent Sun Protective Knowledge, Attitudes and Behaviors in the US. J Prim Prev 2018;39(4):371-86. doi: 10.1007/s10935-018-0515-X

77. Dixon H, Borland R, Hill D. Sun protection and sunburn in primary school children: the influence of age, gender, and coloring. Prev Med 1999;28(2):119-30. doi: 10.1006/pmed.1998.0392

78. Wurpts IC, Geiser C. Is adding more indicators to a latent class analysis beneficial or detrimental? Results of a Monte-Carlo study. Front Psychol 2014;5:920. doi: 10.3389/fpsyg.2014.00920

79. Gooden WE, Struble KD. Perceived parental behavior and the social desirability response set. J Youth Adolesc 1990;19(6):605-13. doi: 10.1007/BF01537179

80. Adams MA, Mayer JA, Bowen DJ, Ji M. Season of interview and self-report of summer sun protection behaviors. Cancer Causes Control 2009;20(2):153-62. doi: 10.1007/s10552-008-9229-3 
81. Dobbinson SJ, Jamsen K, Dixon HG, Spittal MJ, Lagerlund M, Lipscomb JE, et al. Assessing population-wide behaviour change: concordance of 10-year trends in self-reported and observed sun protection. Int J Public Health 2014;59(1):157-66. doi: 10.1007/s00038-013-0454-5

82. Køster B, Søndergaard J, Nielsen J, Allen M, Olsen A, Bentzen J. The validated sun exposure questionnaire: association of objective and subjective measures of sun exposure in a Danish populationbased sample. Br J Dermatol 2017;176(2):446-56. doi: 10.1111/bjd.14861

83. Køster B, Søndergaard J, Nielsen J, Olsen A, Bentzen J. Reliability and consistency of a validated sun exposure questionnaire in a population-based Danish sample. Prev Med Rep 2018;10:438. doi: 10.1016/j.pmedr.2018.02.002

84. Hubbard G, Cherrie J, Gray J, Kyle RG, Nioi A, Wendelboe-Nelson C, et al. Sun protection education for adolescents: a feasibility study of a wait-list controlled trial of an intervention involving a presentation, action planning, and SMS messages and using objective measurement of sun exposure. BMC public health 2020;20(1):131. doi: 10.1186/s12889-020-8265-0

85. Kennedy C, Willemze R, de Gruijl FR, Bavinck JNB, Bajdik CD. The influence of painful sunburns and lifetime sun exposure on the risk of actinic keratoses, seborrheic warts, melanocytic nevi, atypical nevi, and skin cancer. J Invest Dermatol 2003;120(6):1087-93. doi: 10.1046/j.15231747.2003.12246.x

86. Glanz K, Gies P, O'Riordan DL, Elliott T, Nehl E, McCarty F, et al. Validity of self-reported solar UVR exposure compared with objectively measured UVR exposure. Cancer Epidemiol Biomarkers Prev 2010;19(12):3005-12. doi: 10.1158/1055-9965.EPI-10-0709

87. Thieden E, Philipsen PA, Wulf HC. Compliance and data reliability in sun exposure studies with diaries and personal, electronic UV dosimeters. Photodermatol Photoimmunol Photomed 2006;22(2):93-9. doi: 10.1111/j.1600-0781.2006.00207.x

88. Vanos JK. Children's health and vulnerability in outdoor microclimates: A comprehensive review. Environ Int 2015;76:1-15. doi: 10.1016/j.envint.2014.11.016

89. Termorshuizen F, Wijga A, Garssen J, Den Outer PN, Slaper H, Van Loveren H. Exposure to solar ultraviolet radiation in young Dutch children: assessment by means of a 6-week retrospective questionnaire. J Expo Sci Environ Epidemiol 2002;12(3):204-13.

90. Christian H, Lester L, Trost SG, Trapp G, Schipperijn J, Boruff B, et al. Shade coverage, ultraviolet radiation and children's physical activity in early childhood education and care. Int J Public Health 2019;64(9):1325-33. doi: 10.1007/s00038-019-01289-y 


\section{Supplementary Tables}

Table 3. Socio-demographic characteristics and class-profiling

\begin{tabular}{|c|c|c|c|c|c|}
\hline & $\begin{array}{c}\text { Best class } \\
(n=288 \\
18.5 \%)\end{array}$ & $\begin{array}{c}\text { Second best } \\
\text { class } \\
(\mathbf{n}=726 ; \\
57.5 \%)\end{array}$ & $\begin{array}{l}\text { Poorest class } \\
(n=53 ; 4.6 \%)\end{array}$ & $\begin{array}{c}\text { Intermediate } \\
\text { class } \\
(\mathrm{n}=232 ; \\
19.4 \%)\end{array}$ & \\
\hline & $\mathbf{n}(\%)$ & $\mathbf{n}(\%)$ & $\mathrm{n}(\%)$ & $\mathrm{n}(\%)$ & $\begin{array}{c}p \text {-value } \\
\text { (Chi- } \\
\text { Square) }\end{array}$ \\
\hline $\begin{array}{l}\text { Parents' } \\
\text { characteristics }\end{array}$ & & & & & \\
\hline Age & & & & & .003 \\
\hline - $\quad$ Young & $53(18.4)$ & $102(14.0)$ & $6(11.3)$ & $21(9.1)$ & \\
\hline - $\quad$ Middle-aged & $182(63.2)$ & 449 (61.8) & $27(50.9)$ & 143 (61.6) & \\
\hline - $\quad$ Older & $53(18.4)$ & $175(24.1)$ & $20(37.7)$ & $68(29.3)$ & \\
\hline Sex & & & & & .220 \\
\hline - $\quad$ Male & $110(38.2)$ & $286(39.4)$ & $26(49.1)$ & $104(44.8)$ & \\
\hline - $\quad$ Female & $178(61.8)$ & $440(60.6)$ & $27(50.9)$ & $128(55.2)$ & \\
\hline Skin type & & & & & $<.001$ \\
\hline $\begin{array}{l}\text { I: burns very } \\
\text { quickly }\end{array}$ & $31(10.8)$ & 77 (10.6) & $2(3.8)$ & $9(3.9)$ & \\
\hline $\begin{array}{ll}\text { - } & \text { II: burns } \\
& \text { quickly } \\
\end{array}$ & $124(43.1)$ & $284(39.1)$ & $12(22.6)$ & $96(41.4)$ & \\
\hline $\begin{array}{ll}\text { III: burns } \\
\text { rarely }\end{array}$ & $114(39.6)$ & $322(44.4)$ & $30(56.6)$ & $101(43.5)$ & \\
\hline $\begin{array}{ll}\text { - } & \text { IV: burns } \\
\text { almost never }\end{array}$ & $19(6.6)$ & 43 (5.9) & $9(17.0)$ & $26(11.2)$ & \\
\hline Education & & & & & .118 \\
\hline - $\quad$ Lower & $36(12.5)$ & $102(14.0)$ & $11(20.8)$ & $43(18.5)$ & \\
\hline - $\quad$ Intermediate & $111(38.5)$ & $278(38.5)$ & $20(37.7)$ & 69 (29.7) & \\
\hline - $\quad$ Higher & $141(49.0)$ & $343(47.2)$ & $21(39.6)$ & $120(51.7)$ & \\
\hline Province & & & & & .135 \\
\hline - $\quad$ North & $19(6.6)$ & $68(9.4)$ & $2(3.8)$ & $19(8.2)$ & \\
\hline
\end{tabular}




\begin{tabular}{|c|c|c|c|c|c|}
\hline - $\quad$ East & $74(25.7)$ & $162(22.3)$ & $8(15.1)$ & $61(26.3)$ & \\
\hline - $\quad$ South & $132(45.8)$ & $308(42.4)$ & $33(62.3)$ & $100(43.1)$ & \\
\hline - West & $63(21.9)$ & $187(25.8)$ & $10(18.9)$ & $52(22.4)$ & \\
\hline \multicolumn{6}{|l|}{$\begin{array}{l}\text { Children's } \\
\text { characteristics }\end{array}$} \\
\hline Age & & & & & $<.001$ \\
\hline - $\quad$ Young & $172(59.7)$ & $326(44.9)$ & $15(28.3)$ & $82(35.3)$ & \\
\hline - $\quad$ Middle-aged & $71(24.7)$ & $221(30.4)$ & $22(41.5)$ & $71(30.6)$ & \\
\hline - $\quad$ Older & $45(15.6)$ & $179(24.7)$ & $16(30.2)$ & $79(34.1)$ & \\
\hline Sex & & & & & .945 \\
\hline - $\quad$ Boy & $145(50.3)$ & $366(50.4)$ & $25(47.2)$ & $120(51.7)$ & \\
\hline - $\quad$ Girl & $143(49.7)$ & $360(49.6)$ & $28(52.8)$ & $112(48.3)$ & \\
\hline Skin type & & & & & .001 \\
\hline $\begin{array}{ll} & \text { I: burns very } \\
& \text { quickly }\end{array}$ & $24(8.3)$ & $51(7.0)$ & $1(1.9)$ & $5(2.2)$ & \\
\hline $\begin{array}{ll}\text { - } & \text { II: burns } \\
& \text { quickly }\end{array}$ & $112(38.9)$ & $264(36.4)$ & $14(26.4)$ & $76(32.8)$ & \\
\hline $\begin{array}{ll} & \text { III: burns } \\
& \text { rarely }\end{array}$ & $131(45.5)$ & $363(50.0)$ & $29(54.7)$ & $123(53.0)$ & \\
\hline $\begin{array}{ll} & \text { IV: burns } \\
& \text { almost never }\end{array}$ & $21(7.3)$ & $48(6.6)$ & $9(17.0)$ & $28(12.1)$ & \\
\hline
\end{tabular}

\begin{tabular}{|l|l|l|l|l|l|l|}
\hline \multicolumn{1}{|l|}{ Table 4. All model parameter estimates of Multinominal Linear Regressions } \\
\hline & Effect & Estimate & SE & Exp(B) & Wald & $p$ value \\
\hline Class 2 & Intercept & -1.02 & .46 & & 5.00 & .025 \\
\hline & Province (North) & -.40 & .39 & .67 & 1.08 & .30 \\
\hline & Province (East) & -.11 & .26 & .89 & .18 & .67 \\
\hline & Province (West) & -.05 & .24 & .95 & .04 & .84 \\
\hline & Education (Low) & -.18 & .27 & .84 & .44 & .51 \\
\hline
\end{tabular}




\begin{tabular}{|c|c|c|c|c|c|c|}
\hline & $\begin{array}{l}\text { Education } \\
\text { (Intermediate) }\end{array}$ & .41 & .21 & 1.51 & 4.02 & .052 \\
\hline & $\begin{array}{l}\text { Parental age } \\
\text { (Young) }\end{array}$ & .42 & .36 & 1.52 & 1.39 & .24 \\
\hline & $\begin{array}{l}\text { Parental age } \\
\text { (Middle-aged) }\end{array}$ & .05 & .24 & 1.05 & 0.46 & .83 \\
\hline & $\begin{array}{l}\text { Parental sex } \\
\text { (Male) }\end{array}$ & -.28 & .19 & .76 & 2.13 & .14 \\
\hline & $\begin{array}{l}\text { Parental skin } \\
\text { type (I) }\end{array}$ & 1.05 & .55 & 2.87 & 3.71 & .054 \\
\hline & $\begin{array}{l}\text { Parental skin } \\
\text { type (II) }\end{array}$ & .26 & .40 & 1.30 & .43 & .51 \\
\hline & $\begin{array}{l}\text { Parental skin } \\
\text { type (III) }\end{array}$ & .24 & .39 & 1.27 & .37 & .54 \\
\hline & $\begin{array}{l}\text { Child's age } \\
\text { (Young) }\end{array}$ & 1.18 & .26 & 3.24 & 20.47 & .00 \\
\hline & $\begin{array}{l}\text { Child's age } \\
\text { (Middle-aged) }\end{array}$ & .44 & .26 & 1.55 & 2.76 & .10 \\
\hline & $\begin{array}{l}\text { Child's sex } \\
\text { (Boy) }\end{array}$ & -.11 & .18 & .90 & .35 & .55 \\
\hline & $\begin{array}{l}\text { Children's skin } \\
\text { type (I) }\end{array}$ & 1.35 & .63 & 3.86 & 4.67 & .03 \\
\hline & $\begin{array}{l}\text { Children's skin } \\
\text { type (II) }\end{array}$ & .46 & .39 & 1.58 & 1.41 & .24 \\
\hline & $\begin{array}{l}\text { Children's skin } \\
\text { type (III) }\end{array}$ & .19 & .37 & 1.21 & .26 & .61 \\
\hline Class 3 & Intercept & .27 & .37 & & .57 & .45 \\
\hline & Province (North) & -.14 & .31 & .87 & .19 & .66 \\
\hline & Province (East) & -.42 & .22 & .66 & 3.46 & .06 \\
\hline
\end{tabular}




\begin{tabular}{|c|c|c|c|c|c|c|}
\hline & Province (West) & -.24 & .20 & .79 & 1.47 & .23 \\
\hline & Education (Low) & -.11 & .22 & .89 & .26 & .61 \\
\hline & $\begin{array}{l}\text { Education } \\
\text { (Intermediate) }\end{array}$ & .38 & .18 & 1.46 & 4.62 & .32 \\
\hline & $\begin{array}{l}\text { Parental age } \\
\text { (Young) }\end{array}$ & .28 & .31 & 1.32 & .78 & .38 \\
\hline & $\begin{array}{l}\text { Parental age } \\
\text { (Middle-aged) }\end{array}$ & -.00 & .19 & 1.00 & .00 & .99 \\
\hline & $\begin{array}{l}\text { Parental sex } \\
\text { (Male) }\end{array}$ & -.24 & .16 & .79 & 2.26 & .13 \\
\hline & $\begin{array}{l}\text { Parental skin } \\
\text { type (I) }\end{array}$ & 1.17 & .47 & 3.23 & 6.18 & .01 \\
\hline & $\begin{array}{l}\text { Parental skin } \\
\text { type (II) }\end{array}$ & .28 & .32 & 1.32 & .74 & .39 \\
\hline & $\begin{array}{l}\text { Parental skin } \\
\text { type (III) }\end{array}$ & .44 & .31 & 1.55 & 1.96 & .16 \\
\hline & $\begin{array}{l}\text { Child's age } \\
\text { (Young) }\end{array}$ & .48 & .21 & 1.6 & 5.20 & .02 \\
\hline & $\begin{array}{l}\text { Child's age } \\
\text { (Middle-aged) }\end{array}$ & .24 & .20 & 1.27 & 1.34 & .25 \\
\hline & $\begin{array}{l}\text { Child's sex } \\
\text { (Boy) }\end{array}$ & -.10 & .15 & .91 & .41 & .52 \\
\hline & $\begin{array}{l}\text { Children's skin } \\
\text { type (I) }\end{array}$ & 1.32 & .56 & 3.74 & 5.47 & .02 \\
\hline & $\begin{array}{l}\text { Children's skin } \\
\text { type (II) }\end{array}$ & .56 & .32 & 1.75 & 3.10 & .08 \\
\hline & $\begin{array}{l}\text { Children's skin } \\
\text { type (III) }\end{array}$ & .36 & .30 & 1.44 & 1.47 & .23 \\
\hline Class 4 & Intercept & -1.51 & .68 & & 5.00 & .03 \\
\hline
\end{tabular}




\begin{tabular}{|c|c|c|c|c|c|}
\hline Province (North) & -.60 & .83 & .55 & .53 & .47 \\
\hline Province (East) & -.36 & .52 & .70 & .48 & .49 \\
\hline Province (West) & .59 & .41 & 1.80 & 2.06 & .15 \\
\hline Education (Low) & .47 & .43 & 1.60 & 1.20 & .27 \\
\hline $\begin{array}{l}\text { Education } \\
\text { (Intermediate) }\end{array}$ & .51 & .36 & 1.67 & 2.10 & .15 \\
\hline $\begin{array}{l}\text { Parental age } \\
\text { (Young) }\end{array}$ & -.36 & .62 & .70 & .33 & .56 \\
\hline $\begin{array}{l}\text { Parental age } \\
\text { (Middle-aged) }\end{array}$ & -.61 & .36 & .55 & 2.81 & .09 \\
\hline $\begin{array}{l}\text { Parental sex } \\
\text { (Male) }\end{array}$ & .07 & .32 & 1.08 & .05 & .82 \\
\hline $\begin{array}{l}\text { Parental skin } \\
\text { type (I) }\end{array}$ & -.40 & .95 & .67 & .18 & .67 \\
\hline $\begin{array}{l}\text { Parental skin } \\
\text { type (II) }\end{array}$ & -.96 & .60 & .38 & 2.57 & .11 \\
\hline $\begin{array}{l}\text { Parental skin } \\
\text { type (III) }\end{array}$ & -.04 & .53 & .96 & .01 & .94 \\
\hline $\begin{array}{l}\text { Child's age } \\
\text { (Young) }\end{array}$ & .21 & .45 & 1.24 & .23 & .63 \\
\hline $\begin{array}{l}\text { Child's age } \\
\text { (Middle-aged) }\end{array}$ & .69 & .40 & 2.00 & 3.01 & .08 \\
\hline $\begin{array}{l}\text { Child's sex } \\
\text { (Boy) }\end{array}$ & -.18 & .31 & .84 & .33 & .57 \\
\hline $\begin{array}{l}\text { Children's skin } \\
\text { type (I) }\end{array}$ & .02 & 1.23 & 1.02 & .00 & .99 \\
\hline $\begin{array}{l}\text { Children's skin } \\
\text { type (II) }\end{array}$ & .05 & .59 & 1.05 & .01 & .94 \\
\hline
\end{tabular}




\begin{tabular}{|l|l|l|l|l|l|l|}
\hline & $\begin{array}{l}\text { Children's skin } \\
\text { type (III) }\end{array}$ & -.03 & .53 & .97 & .00 & .95 \\
\hline
\end{tabular}

